\title{
Study on Sharing Modes of Teaching Resources in University Town
}

\author{
Shi Mei Hua Zhang Hai Sheng \\ Academic Affairs Office,Donghua University,Shanghai,China,201620 \\ (E-mail:mhshi@163.com,hszhang@dhu.edu.cn)
}

\begin{abstract}
One after another university town has been built nationwide up to date since the turn of 21 st century. Sharing teaching resources, an important idea in the process of programming and designing of the university towns, has been enhancing gradually in various university Towns. the sharing includes the following such as the opening, introduction and cooperation, construction of teaching resources .Based on the case of Song Jiang University Town, proposes the direction of further development and reform in the future by analyzing current teaching resources sharing and its problems and therefore is intended to make significant exploration in this field.
\end{abstract}

Keywords: University town, Teaching resource, Sharing, Openness, Co-building

\section{Introduction}

More than 50 university towns have been built nationwide up to date since the turn of $21^{\text {st }}$ century for the goal of institutional innovation and enhanced strengths for high education. In the University town of our country, the mode of taking the initiative to build was used notably ${ }^{[1]}$. To some extent, the sharing of teaching resources tops the list of the planning of university town, which solved the shortage of the teaching resources in the development process of higher education ${ }^{[2]}$.Centralization of universities campuses and overlapping of majors, disciplines of different universities, which is characteristic of university town, pave a way for the realization of the innovation of knowledge and sharing of teaching resources $^{[3]}$.

Since the establishment of university town, the sharing of teaching resources has been promoted progressively. Now, the sharing includes the following such as the opening, introduction and cooperation, construction of teaching resources ${ }^{[4]}$. However, the sharing and cooperation now is still at its first stage of openness, such as the sharing of first class courses and lectures, for which there is a long way to go for the goal of the ideal of sharing teaching resources.

For the time being, the implement of sharing teaching resources is conducted by the Office of
Teaching Affair, which decides the teaching resources to be shared, posting information and enrollment etc. However, due to a lack of proper coordination and supervision mechanism, the sharing is quite difficult to be carried forward for it requires joint efforts from multiple departments. In fact, teaching resources refer to not only teaching at all levels, but it concerns interests of each university as well. Therefore, educational authorities have to take the lead to further promote the sharing of teaching resources and motivate universities to build a long-term coordination mechanism. And to achieve an overall supervision and coordination of sharing, the mechanism should cover teaching affairs, human resources management such as inter-school-employment, and laboratory management like dealing with loss of common facilities, as well as Administration Committee of University Town's appraisal and assessment towards teaching resources of each university. Only on the basis of the principle of "sharing interests and mutual benefit" can this mode be successfully carried out.

And then how could the sharing of teaching resources effectively promote in university town? First and foremost, the establishment of systems is the key to success. A new prospect for the sharing of teaching resources will be ensured through the establishment of effective mechanisms of cooperation and coordination, stabilization and upgrading of the current mode and its sustaining development and innovation.

\section{Status Quo Analysis of Teaching Resources Sharing in University Town}

The opening of teaching resources, free access to the college students, assures students in and out of university town of a free access to teaching resources from various universities. In the meanwhile, it encourages students to share quality teaching resources, for instance, featured courses and lectures in university town as a whole. The introduction to and cooperation of teaching resources involves the introduction of quality faculty from other universities in town as well as cooperative education like exchange students programs, etc. And shared construction of teaching resources primarily refers to the sharing in a series of fields including quality courses, construction and sharing of experimental sites, teaching and research sections. 


\subsection{The Sharing of Courses and Lectures}

Now that universities in the university town differ in educational levels and disciplinary requirements, it is too premature and unrealistic to share courses on a large scale. Currently, the opening and sharing in university town is based on a new series of inter-university optional courses offered by leading discipline of each university to satisfy the need of society. In this way, the diversified cultures of university town are widely experienced among students. While during the process, the approach of "Making Progress on a System Guarantee Basis" is adopted to promote shared courses in quantity, quality and features ${ }^{[5]}$.

Besides, the opening and sharing of lectures fully displays the advantages of university town in the way of centralization of campuses, the maximization of efficiency of lectures available to students and cultural blending of different universities.

At present, the courses and lectures shared in town have a great influence with its greatest coverage of different universities, students of different levels and grades, which guarantee the realization of the goal of sharing and display different features and preserve independence of each university, thus it enjoys its leading status both in influence and priority in the agenda of university town as well. Therefore, the top priority now should be given to strengthening teaching coordination and management such as class reschedule for holidays, teaching appraisal for open courses, and occupancy rate of lectures, etc.

\subsection{The sharing of Minor System}

In the early 1990s, Minors were initiated and put into practice by some key universities. The minor system is an important approach for colleges and universities to nurture interdisciplinary talents by encouraging students of aptitude to take up minors while fulfilling their majors. Therefore, with the promotion of major-minor system in university town, even students from ordinary universities in town secure access to quality teaching resources of key universities, which substantially enhances the exchanges and progress among students of different levels and the fostering of interdisciplinary talents. However, the minor system is also facing problems including a narrow breadth of courses mostly on disciplines such as Management, Economics, and Languages, and other problems such as over-intensive teaching hours and a lack of course practices for minors. Therefore, some improvements and reform must be made to reinforce current teaching mode scientifically and rationally, in an effort to create active learning atmosphere for students to develop individualities and to propel a comprehensive quality education in university town.

\subsection{Promoting Exchange Students Program to Achieve a Win-Win Sharing of Teaching Resources}

Exchange students program, is literally known as inter-university cooperative education which utilizes disciplinary advantages of each university to exchange students within university town. The management of exchange students largely relates to teaching management of students rather than that of students' accommodation or else. Take Songjiang University Town as an example, Law majors from Donghua University exchange in class unit with students of Computer Science and Technology from East China University of Political Science and Law to further their own major studies for one year. In this way, not only credits and courses are mutually acknowledged, but also complementary advantages could be achieved. Therefore, the mode of fostering excellent students via inter-school cooperation should be constantly deepened and promoted to benefit more students in university town.

In addition, a win-win sharing of teaching resources could be achieved through the development of specialties by disciplinary blending. Universities are able to jointly carry out major teaching and research projects and the sharing of disciplinary resources with a disciplinary consultation mechanism on a regular basis. With the inter-university cooperation in university town, each university could bring in the excellent teaching resources from others in town, achieve complementary advantages and resource sharing, optimize its resources and reduce the cost of running of universities.

\subsection{The sharing of teaching laboratory resources}

Each university in town has invested significantly in building teaching laboratories of its own. If the resources could be fully utilized and shared, redundant construction could be avoided. Meanwhile quality teaching resources could be accessible to more students in university town. Under the circumstance of open laboratory resources, more students will benefit as they get more opportunities to improve their practical capabilities. Likewise, in the case of opening laboratories of high quality and offering courses of practice to students, they are able to integrate theories with practices and benefit from featured laboratory resources from other universities.

\subsection{The Fostering and Sharing of Quality Courses in University Town}

To vigorously foster quality courses, it's of great significance to combine the highly complementary features of quality courses in each university. With joint efforts from a couple of universities, the quality courses could not only benefit students but also help teachers in teaching groups grow faster to maturity and improve their teaching. For this reason, education commission is supposed to give priority to the approval, initiation and input of shared courses when verifying applications for best courses at municipal and national levels to mobilize teachers' enthusiasm for co-built courses. Hence a series of best courses of university town could be shared while teaching quality could thus be improved. 
2.6. The co-building of Teaching and research sections for Basic Courses

As universities in university town vary in levels and teaching quality, the key universities should play a leading role in the establishment of teaching and research sections to promote the teaching quality of basic courses. For instance, teaching and research section for English regularly organizes activities like teaching assessment, evaluation, etc to improve quality of English teaching; and that for Mathematics strengthens researches on teaching by organizing Advanced Mathematics competitions within the town. In spite of that all these activities have, to a large extent, helped push forward teaching reform in university town, no significant progress have been made so far in this area due to lack of coordination in building of teaching and research sections, different requirements, especially concern of key universities that teaching quality might drop.

\section{The Innovation and Development of Sharing Mode in the Future}

\subsection{Deepening the existing sharing mode and perfecting} the network of sharing management platform

The new mode of cooperative education in university town offers brand-new ideas and approach for universities to further reform and development. So, the highlight of work in the future should be, first of all, to deepen the existing sharing mode of teaching and to improve the current management. To put it more specific, the sharing of teach resources should be equipped with an exclusive network of management platform, on which registrations of shared courses and lectures, minors, and application for quality courses could be managed. At the same time, this platform could interoperate with management platform of education service in each university to enhance the extent of informationization of teaching service. With the interpretability of online courses platform, a relatively integrated resource center for data of education management and online courses will be set up in each university. And resource center of online courses is an effective pathway to optimize excellent resources from each university.

\subsection{Sharing of Excellent Teachers}

An information bank for inter-university employment should be set up for the establishment of a network of sharing excellent teachers. Universities ought to fully exploit resources of excellent teachers in university town, expand students' access to excellent teachers and lay a foundation for goals of complementation of different disciplines and teachers through inter-university employment. Moreover, in order to guarantee teaching quality in other universities, teachers' performance should be mutually acknowledged within university town.

Meanwhile, foreign teachers should be introduced to university town and a database for them should be set up. By dint of resources sharing of foreign teachers, international curriculums and teaching in English, bilingual teaching could be launched in university town. Therefore, students share not only the excellent education resources within town but also influence brought by excellent resources overseas, which in turn, further enhances the internationalization of education.

\subsection{Construction of the platform for courses of practice in university town}

Under the auspice of high-quality teaching laboratories, and through integrating each university's special courses, establishing platform for practical courses, and opening special practical courses for students in university town, laboratory resources could be fully harnessed to benefit more students and improve their practical capability. A case in point is Songjiang University Town. It may combine all featured laboratory resources inside it to open laboratory courses such as Simulated Tour Guides, Moot Court, Electric Forensic, and Metallic Materials Machining, Technology of Printing, which will distinguish itself from other university town.

\subsection{Establishing a sharing mode of teaching resources between university towns}

Owing to diverse regions and culture of different university town, there is a possibility for them, to operate a resources-sharing mode in university town units, which will enlarge the scale of resources sharing and increase the extent of open education of universities. But the resources-sharing mode is barely open operated across university towns. In the early 2012, and under the respective leadership of Education Commission, Songjiang University Town, Hangzhou Xiasha University Town in Yangtze River Delta Region and Nanjing Xianlin University town initiated the mode of exchange students. In this mode, each university town recommends excellent students for one semester or one academic year's study to the brand specialties opened in three university towns. Though it's still in pilot phase and not widely available to students, it has already won profound acclaims from society. Therefore, continuous efforts must be made to constantly deepen and perfect the management system of exchange students.

However, due to multiple management problems like students' accommodation, and credits recognition resulting from one semester or academic year of exchange period, the mode of exchange students could only benefit a small number of students. Therefore, university town could offer some brand courses focusing on practice, humanistic quality and competition in summer vacation, as accommodation is vacant and a short but intensive class schedule is possible. In this way, the cultural exchanges and openness between university towns will be significantly improved. 


\section{Conclusion}

To deepen the sharing of teaching resources calls for cooperation from different universities in university town. And the exploration and research on new modes for cooperative education should be future-oriented and development-oriented to achieve regional advantages by deepening coordination and establishing "Community of Specialties, Community of Resources" ${ }^{[6]}$. Therefore, the educational authorities are responsible for the elimination of obstacles in the way of resources sharing and create a favorable environment for it. To achieve this end, active measures must be taken to explore a balanced benefit distribution approach and make preferential policies to enhance initiatives of each university and pool their wisdom and efforts.

\section{Acknowledgement}

Supported by the Research Fund for National Social Science of Education （CIA110136).

\section{Reference}

[1] Hu Haijian. On Primary types of University Town Overseas [J] Higher Education Exploration, 2007(3):58-62 (In Chinese)

[2] Zhujin, Lin Hanwu. Research on University Resources Sharing Based on the Mode of University City[J] Xi'an University of Architecture and Technology (Social Sciences Edition),2006(1):93-96 (In Chinese)

[3] Dai Xiaopeng, Huanghuang. Study on Technology of Knowledge Sharing Space of Knowledge-based Organization [J] Journal of Information, 2008(2):82-85(In Chinese)

[4] Li Haiping, The Sharing of Teaching Resource: Problems and Solutions [J] Beijing Education (Higher Education Version), 2003(9):30-32 (In Chinese)

[5] Zhengwen, Li Wenlin, A Preliminary Research on Ideas, Layers, and Strategies of Teaching Resources Sharing in University Town [J] China University Teaching, 2006(6) :20-21(In Chinese)

[6] Xiao Xingyan. Discussion on the Content, Features and Functions of University Town System [J] Journal of Educational Development, 2008(6) :14-17(In Chinese) 